\title{
RADICAI TEACIFR
} A SOCIALIST, FEMINIST, AND ANTI-RACIST JOURNAL ON THE THEORY AND PRACTICE OF TEACHING

\section{Radical Scaffolding Against Critique Fatigue}

\author{
by Eva Boodman
}

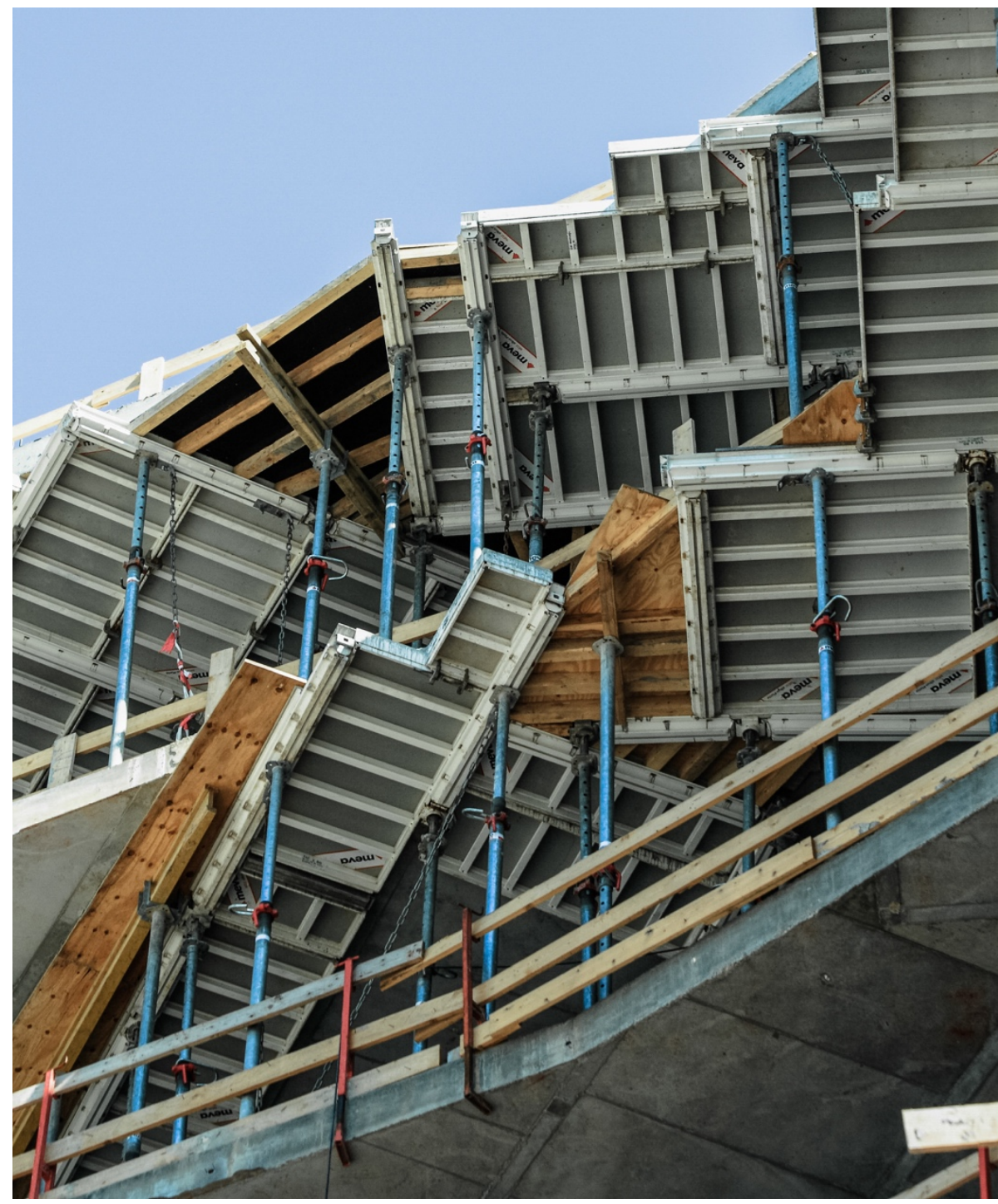

PHOTO BY JENS RADEMACHER 


\section{Critical pedagogy and critique fatigue}

On an afternoon last November, I was met with an unusual awkward and heavy atmosphere when I walked into my gender studies classroom in the public university where I then taught. I felt it right away, even though class hadn't yet started, and it was all the more noticeable because the group had thus far been good-natured and engaged. Chalking it up to the fact that it was "that time" of the semester, I plunged head-on into my lesson plan. We were discussing Siobhan Somerville's paper "Scientific Racism and the Emergence of the Homosexual Body," which looks at how racial categories as we know them developed in tandem with, and inseparably from, categories for homosexuality in the nineteenth century. I had thought the paper fascinating. It brought a whole new angle to our class project of understanding the relationship between gender and technologies, not to mention the fact that it would prompt an interesting discussion about what to do with the nefarious origins of the identity categories we use! I asked the students to get into small groups and to break down the connections offered in the text between racial categories and categories for sexual deviance, to then present them to the class. But (as some readers may have already guessed), something wasn't working. The class was quiet; out of respect for me, I believe, the students went through the motions of the activity, but they were clearly uncomfortable. Without saying so, they made it known that they did not want to be having this conversation about queerness and race. When I asked them what was going on, one student said angrily, "I just don't see why we're reading a text that doesn't offer anything new to the analysis!" Another student said, with exasperation, "Yeah, okay, we know, racism exists! Why do we keep reading about it if there's nothing we can do about it?"

Now, before I continue, a couple of things are important to mention. The first is that I am a white, "masculine"-ofcenter gay woman who was then occupying the complicated position of teaching courses on gender, race, and power to classrooms that are majority black and brown students - a reality that was commonplace at my institution, and especially in my own retrograde discipline of philosophy (if race and gender are being discussed at all). One obvious explanation for my students' responses is the defensiveness and exhaustion resulting from that historically loaded setup: having to contend with potentially traumatizing material about racialization in an environment controlled by a white woman, who was evaluating them in the context of a punitive institution meant to train them in respectability. The racialization of school is certainly central to this story: many institutions of higher education function to inculcate students into white, middle-class normativity. What I want to focus on, though, is a sub-dimension of the situation that is less obvious, less written about, and potentially more applicable to those who don't share my social position. The problem to which I'm responding in this essay is a phenomenon I'm going to call "critique fatigue": the discouragement, demoralization, and disempowerment that groups of students may collectively experience when there is too much "critical" content (that is, content aiming to reveal and explain the patterns and mechanisms of oppression) and not enough structured skill-building to allow students to respond creatively, emotionally, practically, and politically/institutionally to the information they are being asked to take in - even if, and especially if, it relates to their own experience.

In the case of my own critique-heavy class, immediately prior to Somerville's essay, the students had read Sarah Haley's work about the state of Georgia's post convictleasing practice of paroling black women into unpaid domestic labor, a text on the suppression of midwives, and Dorothy Roberts' Killing the Black Body, which documents the racism built into the US construal of reproductive rights. These texts are important, and I would teach them again, but only with adequate support for students to use those texts in a structured creative writing or "making" process centered around their own interests and goals-where by "making", I mean forms of creative cognizing not limited to traditional or formulaic essays, or even to reading and writing, alone. ${ }^{1}$ Without a guided "making" process, students begin to feel trapped in the structures and patterns of racial capitalism being constantly hammered out in the course content - a sense of entrapment that is consistent with the way anti-racist teaching and inquiry in the humanities tends toward "damage-centered research" that traffics in the pain narratives of the groups to which many working class, racialized, or otherwise academically underrepresented students belong. ${ }^{2}$ The inadvertent result of overloading students with critical analyses without providing any outlet, is that the patterns of structural racism, classism, and colonialism get reenacted in classrooms where professors think they know what students' own goals are, and assume that "critique" - using reading and writing to identify and describe the structural harms affecting oppressed groups is one of them. While it is important to identify oppressive structures and processes, oftentimes academic "critiques" do this by recirculating "tropes of dysfunction, abuse and neglect" suffered by those marginalized by institutions of higher education. This kind of critique can be fatiguing because, as Tuck and Yang argue, it acts as a reproduction of settler colonial theft and appropriation. ${ }^{3}$ As bell hooks writes of this phenomenon, "no need to hear your voice when I can talk about you better than you can speak about yourself. No need to hear your voice. Only tell me your pain. I want to know your story. And then I will tell it back to you in a new way. [...] I am still author, authority. I am still colonizer the speaking subject and you are now at the center of my talk." 4 This is to say that while some "critique" may 
serve students well, if it is not integrated into a larger process whereby students gain some knowledge, control, and power over their own learning (and their own learning environment), it can have some unintended and undesirable effects.

And this is where the assumptions of Freireian critical pedagogy, while well-meaning, can reinforce critique fatigue. Critical pedagogy rooted in Paolo Freire's Pedagogy of the Oppressed tends to focus on Freireian "critical consciousness," or concientizaçao, wherein education involves understanding one's social situatedness in order to engage in collective, transformative praxis that reconciles social and political contradictions through revolutionary dialogue. This kind of "education for liberation" begins with a "thematic investigation" undertaken by the educator about the problems most affecting those involved in the educational process and ends with the oppressed leading a "cultural revolution" that reconciles teacher and student, oppressor and oppressed, to create a new material reality. ${ }^{5}$ Without delving too deeply into the jargon, details, and problems with Freire's Pedagogy of the Oppressed, it is clear that it is primarily a guide for undertaking popular education on a dialectical (Marxist) model.

\section{No matter how "progressive" a college and its faculty may seem, the neoliberal university is not the revolutionary terrain intended by Pedagogy of the Oppressed, and treating it as though it is can paradoxically be a great disservice to students - especially students who grew up poor, are BIPOC, immigrants, first generation, or have a disability - who may have political goals and visions of liberation different from the Freireian professor.}

There is much to like about Freire and Marxist popular education, and some of its dimensions can indeed be translated for college humanities classrooms, but it is also true that higher education is a professionalized, professionalizing, and therefore, fundamentally classconservative environment. ${ }^{6}$ No matter how "progressive" a college and its faculty may seem, the neoliberal university is not the revolutionary terrain intended by Pedagogy of the Oppressed, and treating it as though it is can paradoxically be a great disservice to students - especially students who grew up poor, are BIPOC, immigrants, first generation, or have a disability - who may have political goals and visions of liberation different from the Freireian professor. As Fred Moten and Stefano Harney write, the "critical academic" is bound to ignore the diversity of un-unified goals, skills, and experiences in a classroom of students who are revolutionary in their small-scale, disorganized forms of theft, refusal, disruption, and passion ${ }^{7}$-and this is especially the case because of the critical academic's bourgeois complicity with institutional power and class benefit.
Treating the realities of race, class, and colonialism as discernable or disclosable primarily through "critique" without an "application" can have the additional paradoxical effect of silencing students who may have their own direct, first-hand accounts of how something like "structural racism" or "colonialism" happens or of allowing their voices to be "heard" only if they reify their position as subaltern. The Freirian technique of "thematic investigation" - a kind of reconnaissance, undertaken by a revolutionary organizer/educator not indigenous to a given oppressed community, whereby the interests and problems of that community are discussed - could, in this light, put students who are members of underrepresented groups in the uncomfortable, and unethical, position of having to act as "native informants", bringing community knowledge and experience into a context that has been known to appropriate it for the purposes of institutional prestige and career advancement.

For these reasons, to have something like "structural racism" be the takeaway of a course or a lesson can be patronizing (or even worse, potentially re-traumatizing) if it is not accompanied by a structured process of creative output, planning, and conversation through which some of the learning goals and thematic agenda are set by the students themselves. It's important to note that Freire himself was committed to joining the "theoretical" with revolutionary praxis, or the collective, dialectical activity of targeting a set of structures or structural forces identified through critical consciousness. This project is definitely a good one. But it's unclear how this praxis translates for students who may earnestly need support to get through the requirements of college. Cultivating a set of choices for how that can be done in such a non-revolutionary environment would be a much-needed addition to the Freirian critical pedagogy approach.

Traditional critical pedagogy is not a harm-reduction method. And for that reason, it can sometimes ignore the ways that a structured, process-oriented approach to creative writing can not only help students develop selfaware "respectability" strategies for meeting "learning objectives" and curricular requirements in the humanities (should they want to, and many do); it can also support students in meeting other self-established goals that range from simply passing the course, to self-expression, selfadvocacy, and survival in a punitive institutional environment that was mostly not set up for their success. Where critical pedagogy in the Freirian tradition is helpful for initiating a conversation about the "big picture" structural circumstances affecting students' experiences inside and outside of class, in a classroom context it can have a tendency to de-emphasize the forms of "cultural revolution" that students are already undertaking for their own survival - like a current student of mine who does not have time to do the reading for our course, but who is waging a quiet war against the college president to change the school's policy on de-enrolling students who cannot afford to pay their fees on time.

In classrooms where there is an emphasis on structural analysis and critique that reveals systemic racism, sexism, and settler colonialism, process-oriented creative writing can recognize and use the cognitive, emotional, and cultural 
knowledge and skills students bring. When students have choices about how they engage with this process, the motor of political meaning is shifted into their hands. This is why, in a way that may seem counter-intuitive to both proponents of radical pedagogy and critical pedagogy, I'm going to make the case for what I call "radical scaffolding": a series of gradual, peer-supported steps or platforms by which students develop skills by building on what they already know. Radical scaffolding decreases students' academic alienation through choice and autonomy, connects critique to creative action and interpretation, disconnects writing from the punitive formulas of an institutional context, and can be thought of as a context-specific means of carrying out some of the more important insights of critical pedagogy in a way that avoids making patronizing assumptions about what "liberation" and "education" mean to adult students.

\section{2. "Traditional" scaffolding}

"Scaffolding" is a useful concept from education theory in need of a serious update. The term, in its more standard sense (different from the "radical" sense I want to propose), is used in current pedagogical theory to describe a structured, collaborative learning process whereby learners transition from knowing how to do something only with "more capable" assistance, to being able to do it independently. The term is often associated with psychologist Dov Vygotsky's pedagogical theory - another form of Marxist critical pedagogy, which understands learning not as undertaken by individuals, but through activities situated in an historical and social context. ${ }^{8}$ Vygotsky is most well-known for his concept of the "zone of proximal development" (ZPD) where learners have some understanding of a task or skill, but haven't yet appropriated or integrated that understanding in a way that would allow them to undertake it without help. Ideas that tend to be taken up by contemporary educators and pedagogical theorists from Vygotsky's work are the notion that learning doesn't just happen through modeling and imitation by individuals, but through a process where peers have an important role in bringing learners out of a ZPD and into the practice of a skill through a collaborative, reflective process - a practice that, for Vygotsky, "confirms personal development as an evolutionary force, history's complement."

This usage of scaffolding is important for an inclusive classroom, and for students' survival in college, since it doesn't assume that all students arrive with the same skillset - though it does, problematically, assume a hierarchy of skills and skill development, where "better" students help "less skilled" others along. The term was originally coined by educational psychologists Wood, Bruner, and Ross in 1976 to describe the transition out of a ZPD, a process whereby the educator controls "those elements of the task that are initially beyond the learner's capacity, thus permitting him [sic] to concentrate upon and complete those elements that are within his range of competence. ${ }^{10}$ In this process, learners engage in a structured dialogue where they are guided both by a teacher and by peers who have better "mastered" the skill. On this traditional definition, scaffolding understands that learning is "not merely conveyed, but mutually created" through reflection and meta-cognition of the learning process itself, resulting in "autonomous" performance of a skill.

In a classroom context where most students went to "teach to the test" public schools and are the first in their families to go to college, this original iteration of scaffolding is important. In order to learn in our classes and to survive their college years, students need support in developing a relationship to reading and writing, and most professors in the humanities are not expecting to have to provide this kind of support. While the "kids these days" complaints are common to hear from professors, I have yet to meet a single $\mathrm{PhD}$ student in the humanities who received any kind of training in addressing what many professors perceive, problematically, to be a kind of learning deficiency. The assumption is that students should come to college with a very particular reading and writing skills in hand, and that if they don't, it isn't our responsibility: a widespread attitude that amounts to punishing students who grew up poor, did not have access to college enculturation in their family or community context, and may have the unrecognized skill of being multi-lingual or speaking and writing in languages or dialects other than standard English - a skill widely seen in academic settings as a deficiency rather than the asset that it is. To punish these "less masterful" students with low grades in writing-intensive courses simply reinforces the historical segregation of the education system by race and class and further discourages students' meaningful relationship to reading and writing. In this way, a scaffolded learning process that brings students from point $A$ to point $B$ through dialogue, feedback, and meta-reflection can be a very effective technique for inclusive college education that builds skills beyond the critique-fatiguing recognition of structural racism through theory.

\section{3. "Radical" scaffolding for creative autonomy beyond "proficiency" and "effectiveness"}

This original iteration of scaffolding is very useful for creating a classroom environment where students can build collaboratively on what they already know, and it's an especially important concept for professors in the humanities who don't have any training in teaching students writing. I want to take the idea of scaffolding further, though, to move it beyond its "effectiveness" and "mastery" bias and into more transformative territory critical of the way these categories are used in the white-normative, middle-class-conservative college environment. This is not to be cynical about effective writing instruction - I have found that students appreciate, and learn better, when there is a clear set of steps, models, drafts, and feedback built into writing assignments. This idea, while rarely taken up by humanities professors, is not new. Teachers of academic writing like John C. Beam ${ }^{11}$ and Nicole Boudreau-Smith have articulated how powerful scaffolded writing instruction can be insofar as it helps students adopt strategies (planning, creating, revising, editing) rather than formulas (like the five-paragraph essay). Boudreau-Smith writes that scaffolding empowers students' relationship to their own 
learning process by "maximizing student responsibility and minimizing teacher control,"12 and develops their "proficiency" by orchestrating "activities and lessons that meet students' level of development and appeal to their passions and concerns". When broadened to include a set of choices about students' political relationship to the institution, and expanded to include goals less limited than "proficiency", this kind of structured skill-building can truly be radical - and I will explain why and how.

"Radical scaffolding" may seem to be a bit of a pretentious coinage, but the term does capture the flexibility and political orientation I intend. Traditional scaffolding, and the way it has been taken up in writing instruction, does the important work of helping students become autonomous in writing skills through a series of peer-guided steps, like brainstorming or visual clustering; peer feedback activities wherein students problem solve in a structured way about issues they are facing with an assignment; and "backwards outlines," through which students evaluate another students' paper by writing a summary sentence about each paragraph and evaluating that outline against a rubric. This kind of instruction could be considered radical in its own right because it gives students tools to develop their own ideas autonomously and creatively in a context that does not train them to do so - and supporting students' creative writing success in punitive contexts that assume their failure is a radical act. But the most radical scaffolding not only teaches skills, but de-hierarchizes the distribution of "skills" in the class so that students are aware of the choices they have when they write in an institutional context- a context deeply structured by, and rewarding of, white middle-class values and behaviors. This expands the notion of "autonomy" to mean not just "accomplishing a task without help", but accomplishing a task by making an active choice about how, and on what motive, that task will be accomplished. Radical scaffolding outlines that set of options and puts the choice in the students' hands without punishing them for what they choose, paying close attention to the context where these choices are taking place, rather than requiring students to write about the patterns of race and class in abstraction from that context. ${ }^{13}$ These options can include any of the following, or several at the same time: survival or passing of the course or of a degree program; pleasure; curiosity; connection and community building with other students; creating political or life strategies, proposals, or manifestos (in response to something in the course, in the institution, or outside of these contexts); skill acquisition; and self-expression.

\section{On my view, it is radical to thematize and de-normalize institutional requirements, giving students choices as to how they will follow them.}

On my view, it is radical to thematize and de-normalize institutional requirements, giving students choices as to how they will follow them. I'm definitely not advocating for "low expectations" here (because students do need to engage and make choices), but rather a way of structuring writing instruction that gradually guides students through different ways of responding creatively to the critical material covered in the course, as well as the forces at work in their own institutional contexts that might impact the way they engage in the activity of writing. I can't claim to have found a perfect or consistent way to do this, and I acknowledge that many instructors may find their own experimentation with radical scaffolding limited by institutional constraints and the official requirements of composition courses, but I have seen some success using these ideas as broad guidelines. In one writing seminar on the theme of education and segregation, for example, I scaffolded by using in-class, low-stakes, peerevaluated writing activities in students' development of a research project of their choice, where every activity had a clear description and instructions, steps and examples to follow, and a checklist, but did not require that students use any particular formula. On this model, students could do the activity in a way that was motivated by their own interests and passions, but if they were not invested in the academic exercise and had other, more important things going on in their lives, could pass the course simply by showing up and doing the activities. Requiring students at a working-class school to demonstrate passion for the classroom activities in order to pass doesn't give students autonomy with respect to the role school has in their lives - though I do think it's important to set students up for creative engagement with the course material and the world around them as an educational priority. While passion and creativity weren't strictly required, most students in that course chose research topics where they had a personal stake: whether to send a child to a charter school, how to navigate white fragility in classrooms as a person of color, how forms of micro-resistance can be a form of non-governmental community control in POC-majority public school districts, and why student debt is the way it is in the US. Even though the course topic was loaded and had a high potential for critique fatigue, the scaffolding gave students the support to work creatively and autonomously with their peers in response to the critique being offered, by using their own experiences and interests, through a guided in-class peer feedback process. The atmosphere in this class was very different from the general frustration and despondency of the students in my opening anecdote who were simply asked to break down the argument of an essay on racialization, and the integration of "critique" with creative, scaffolded student-directed "making" made all the difference.

Traditional scaffolding, when employed as a set of sequential, repeated, and peer-led activities, takes as its premise the fact that cognition isn't individual, but involves "the sharing and distribution of mental activity among learners. ${ }^{14}$ What I have called "radical scaffolding" takes a version of this premise as its starting point for a guided, structured, gradual creative writing process centered around what students know, experience, and feel. Where traditional scaffolding gradually helps students become autonomous with respect to an academic skill being learned, radical scaffolding does this while also thematizing students' institutional situation and giving them the autonomy to choose different ways of relating to the course and course material. While the kind of critical pedagogy that "educates" students on the forces taken to affect them most directly can often result in critique fatigue, and assumes that students 
will want to be on board with a particular vision of liberation, radical scaffolding takes structural factors into account by accommodating a range of possible learning goals students may have, that include survival, passing, emotional expression and exploration, political activity on or off campus, and intellectual engagement for its own sake. As Leonardo and Manning write, an updated version of the ZPD that takes the whiteness and middle-classness of college into account can be understood as a "zone of possibility, which, when accomplished appropriately, threatens the hegemony of whiteness, ${ }^{115}$ rather than shoring it up through teaching practices that ask students to simply affirm the scholarly ventriloquism of their lived experience. Supporting college students from academically underrepresented groups in their own notions of success through transparent, step-by-step, non-punitive skill-building, can be a radical act. By giving students options to respond creatively, emotionally, institutionally, and politically to critical material, students are respected and supported as creative political agents in their own learning process. While this may not foment unified revolutionary upheaval on campus on a radical professor's imagined model, it gives students the power, tools, and space to engage in the forms of resistance that are best for them. And in my view, that is where any education for liberation should begin.

\section{Notes}

1 I'm grateful to David Concepción of the American Association for Philosophy Teachers for the idea that inclusive pedagogy should be centered around "doings" and "makings", rather than on content or vague notions of "critical thinking" or "critique". While those at the AAPT don't necessarily mention Vygotskian pedagogy explicitly, this approach is consistent with his theory of education as an "activity-centered environment" that challenges students to "transcend their actual development as autonomous thinkers" in the interests of intervening in the "practical demands of life" (see Leonardo and Manning, p. 9, reference below).

2 Eve Tuck and K. Wayne Yang, "R-Words: Refusing Research", in D. Paris and M.T. Winn, Humanizing Research: Decolonizing Qualitative Inquiry with Youth and Communities. Thousand Oaks, CA: Sage Publications, (2014): 227.

${ }^{3}$ Tuck and Yang, 227

${ }^{4}$ hooks, 1990, cited in Tuck and Yang, 227

5 Paolo Freire, Pedagogy of the Oppressed. New York: Bloomsbury, 2000.

${ }^{6}$ Colleges have an overwhelmingly white and upper-middleclass professorate acting as role-models and advisors for students in a classroom setting that trains and socializes students into the classed and raced behaviors of middleclass professional life. Course content, program design, and ethos, are designed - often without self-awareness according to the priorities, ideas, and interests of the middle-class professionals working in those environments. According to the National Center for Educational statistics, and as reported by Matthew Lynch in The Advocate in 2016, $84 \%$ of full-time professors are white. Seehttps://www.theedadvocate.org/study-nearly-90-

percent-of-full-time-professors-are-

white/\#targetText=According $\% 20$ to $\% 20$ the $\% 20$ National $\%$ 20Center, numbers $\% 20$ decrease $\% 20$ slightly $\% 20$ with $\% 20 f a$ culty. The National Center for Educational Statistics reports that "Black males, Black females, and Hispanic males each accounted for $2 \%$ of full-time professors". See https://nces.ed.gov/fastfacts/display.asp?id=61

${ }^{7}$ Stefano Harney and Fred Moten, "The University and the Undercommons", in The Undercommons: Fugitive Planning \& Black Study. New York: Minor Compositions, 2013.

8 There's much more to say about the Marxist - and specifically Bolshevik - underpinnings of Vygotsky's theory, but it would be too much to take on here.

9 Zeus Leonardo and Logan Manning, "White historical activity theory: toward a critical understanding of white zones of proximal development", in Race, Ethnicity and Education, DOI: 10.1080/13613324.2015.1100988 (2015): 9.

${ }^{10}$ David Wood, Jerome S. Bruner, and Gail Ross, "The Role of Tutoring in Problem Solving", in the Journal of Child Psychology and Psychiatry, Vol. 17 (1976): 89-100.

${ }^{11}$ John C. Beam, Engaging Ideas: The Professor's Guide to Integrating Writing, Critical Thinking, and Active Learning in the Classroom. San Francisco: Wiley, 2011.

12 Nicole Boudreau-Smith, "A Principled Revolution in the Teaching of Writing", English Journal, 106.5 (2017): 17-75.

${ }^{13}$ My view is consistent with Leonardo and Manning's contention that scaffolding and the ZPD are more productively understood as taking place within educational contexts that inculcate students into whiteness.

\footnotetext{
${ }^{14}$ Boudreau-Smith, 72.

${ }^{15}$ Leonardo and Manning, 11.
}

(cc) EY-NC-ND

ULLS D-Serle
This work is licensed under a Creative Commons Attribution-Noncommercial-No Derivative Works 3.0 United States License.

This journal is published by the University Library System of the University of Pittsburgh as part of its D-Scribe Digital Publishing Program, and is cosponsored by the University of Pittsburgh Press. 